\title{
Protection of Whistleblowers in the Workplace. Who Is Protected and Who Is Responsible under the Provisions of the EU Directive 2019/1937?
}

\author{
Zbigniew Hajn ${ }^{1}$ \\ https://doi.org/10.18778/8220-639-5.03
}

\section{Introduction}

When considering the personal scope of whistleblower protection, it is necessary to begin with a few remarks for the sake of order. First, Directive (EU) 2019/1937 of the European Parliament and of the Council of 23 October 2019 on the protection of persons who report breaches of Union law, ${ }^{2}$ as its title implies, concerns the protection of whistleblowers. However, this protection is secondary to its objective expressed in Article 1, which is to protect the public interest by improving the enforcement of Union law and policies in specific areas. ${ }^{3}$ Ensuring a high level of protection for persons who report breaches of Union law should serve this purpose. ${ }^{4}$ Therefore, it is reasonable to conclude that possible doubts as to the personal scope must be clarified bearing in mind the stated purpose of the Directive. Secondly, Article 1 indicates that only whistleblowers are protected, whereas that protection extends also to the other entities mentioned in Article 4(4), namely entities associated with the whistleblower who may suffer retaliation for this reason. However, this is not an inconsistency or oversight by the legislature. Indeed, the protection of related persons is the protection of whistleblowers from indirect retaliation. ${ }^{5}$ Its justification is therefore the protection of whistleblowers. This is also the reason for its scope and conditions under which it is granted.

1 Professor, dr hab., University of Lodz.

2 Hereinafter: the Directive.

3 See wider: W. Vandekerckhove, Is It Freedom? The Coming About of the EU Directive on Whistleblower Protection, Journal of Business Ethics, https://doi.org/10.1007/s10551-021-04771-x, accessed 01/09/2021.

4 V. Abazi, The European Union Whistleblower Directive: A 'Game Changer' for Whistleblowing Protection?, Industrial Law Journal, Volume 49, Issue 4, December 2020, p. 645.

5 Recital 41. 
For the above reasons, the protection of whistleblowers will be referred to in the following remarks as direct protection and the protection of related persons as indirect protection.

Effective protection of whistleblowers depends to an important extent on clearly defining the personal scope of the provisions that regulate it. Issues related to this subject will be presented in part II of this paper. Part III will be devoted to selected problems concerning the entities responsible for carrying out the obligations imposed by law in connection with this protection of whistleblowers.

\section{Who is entitled to protection?}

As already indicated above, in the light of Article 4 of the Directive, a clear distinction is drawn between whistleblowers and those who are protected because they are at risk of retaliation due to their relationship with the whistleblower. This distinction is important. The protection of whistleblowers is broader. This is because it is served by both the provisions ensuring that information can be disclosed through internal reporting, external reporting and public disclosures and the provisions on protection against retaliation contained in Chapter VI. By contrast, the protection of persons vulnerable to retaliation because of their connection with a whistleblower is generally limited to the right to benefit from measures against retaliation where appropriate. ${ }^{6}$

The persons covered by the Directive are protected irrespective of whether they are citizens of the Union or of a third country. ${ }^{7}$

To determine the scope of direct protection, the notion of whistleblower is of primary importance. The Directive does not use this term, although in its recitals the terms "reporting person" and "whistleblower" appear interchangeably. The reason for avoiding the term "whistleblower" in the articulated text of the Directive is, it seems, the difficulty in translating that English term into other languages. I will refer to such a person interchangeably as a "reporter" or a "whistleblower" in the following remarks.

In the broadest sense, a whistleblower is an informant who reveals wrongdoing in an organization in the hope that it can be stopped. However, the Directive adopts in Article 5(7) its own, narrower definition of this concept. According to it, "reporting person" means a natural person who reports or publicly discloses information on breaches acquired in the context of his or her work-related activities. Anyone who meets these requirements by this definition is therefore a whistleblower.

6 Article 4(4) in initio.

7 Recital 37. 
The Directive includes a wide range of persons as whistleblowers, thus fulfilling most of the wishes expressed prior to its issuance. The categories of entities that may be whistleblowers are set out in Article 4(1-3).

In the first place, the Directive includes among whistleblowers workers within the meaning of Article 45(1) TFEU, including civil servants, as persons having the closest links with the institutions in which wrongdoing may occur and, at the same time, because of the subordination and dependence on the employer characteristic of the employment relationship, particularly vulnerable to retaliation. Workers are in a special position. In particular, internal channels should be made available to them on a mandatory basis, whereas they are optional for other categories of whistleblowers. ${ }^{8}$

Among potential whistleblowers, the Directive also includes other persons who may have priority access to certain types of information sources and who, at the same time, may find themselves in a vulnerable situation in the context of their work-related activities. ${ }^{9}$ They include: persons working in the private or public sector, including at least : (-) self-employed workers within the meaning of Article 49 TFEU; (-) shareholders or members of the administrative, management or supervisory body of an undertaking, including non-executive members, as well as volunteers and trainees, whether remunerated or not; (-) persons working under the supervision and direction of contractors, subcontractors and suppliers.

However, important doubts concern the definition of persons entitled to protection in Articles 4(2) and 4(3). These provisions recognise as whistleblowers persons who report breaches of which they become aware after the relationship they had with the legal entity has ended, as well as persons who report breaches concerning information they obtained in the course of recruitment or negotiations prior to the establishment of a legal relationship with the entity. The English version of the text of the Directive defines this relationship as a "work-based relationship". In contrast, many other language versions, including the languages of the countries surveyed, use the term "employment relationship". This difference is important because it leads to a significant differentiation between the circle of whistleblowers and the possibilities of reporting breaches. In our opinion, the relationship indicated above cannot be equated with an employment relationship. It refers to all relations connected with the broadly understood work of persons mentioned in Article 4(1) and other persons who reports or publicly discloses information on breaches acquired in the context of their work-related activities. Such a conclusion is justified by a systematic interpretation of Article 4(1) as a whole and by the purpose of that provision and of the Directive as a whole, which is to create the widest possible opportunities for reporting breaches in a work-related context. ${ }^{10}$

8 Article 8(2).

9 Recital 39 and 40.

10 The correctness of such an interpretation is also confirmed by the last sentence of recital 39, as well as by the Council of Europe's position explaining the use of the same term. Council of Europe, 2014, p. 20. 
It is irrelevant whether the work in the sense described is carried out in the private or public sector. However, the Directive does not cover EU officials, who are not subject to national legislation, but to the EU Staff Regulations. It should, however, apply to them in cases where officials and other servants of the Union report breaches that occur in a work context, but not in the context of their employment relationship with the institutions, bodies, offices or agencies of the Union. ${ }^{11}$

The list of persons who may be considered whistleblowers contained in Article 4 is open-ended. It is illustrative and minimal. Transposition may extend the list but not close it. Protection should be afforded to all who are reporting persons within the meaning of the Directive and who fulfil the conditions laid down therein to benefit from protection. As indicated above, anyone who meets the definition of a reporting person in Article 5(7) is a whistleblower. It is therefore sufficient to be a natural person and to report or publicly disclose information on breaches obtained in the context of one's work. However, this does not mean that every such person will be protected. In order to benefit from protection, a whistleblower must fulfil further conditions. As follows from Article 6 of the Directive, he or she must have reasonable grounds to believe that the information was true at the time of reporting and falls within the scope of the Directive. Moreover, he/she may not be recognized or registered as a paid whistleblower. Finally, whistleblowers may be excluded from protected whistleblowing if they make complaints solely for their own private interest related to a conflict with another person.

The requirement that a whistleblower be a natural person is clear and does not raise interpretation issues. However, it excludes legal persons from the circle of whistleblowers. This limitation seems to be reasonable. ${ }^{12}$ The purpose of the Directive is to protect the public interest in improving the observance of the law by protecting whistleblowers in the context of their work. The specific reporting procedures, support measures and measures for protection against retaliation provided for in the Directive are tailored to achieve this objective. This is in itself a sufficiently important, distinct and specific area for combating breaches of the law that threaten society. On the other hand, whistleblowing by legal entities, such as for example contractors of the wrongdoer or civil society organizations combating fraud and

11 See recital 23. Each EU institution, body and agency adopts its own rules on the basis of an internal administrative rule-making process; see Regulation No. 31 (EEC) 11 (EAEC) laying down the Staff Regulations of Officials and the Conditions of Employment of Other Servants of the European Economic Community and the European Atomic Energy Community [1962] OJ P045/1385. It is therefore alleged that EU workers are protected in a fragmented way, i.e. in a way that the Directive seeks to remedy at national level; see V. Abazi, The European Union Whistleblower Directive: A 'Game Changer' for Whistleblowing Protection?, Industrial Law Journal, Volume 49, Issue 4, December 2020, p. 647.

12 However, this is met with some criticism. In particular, it is argued that granting legal persons the ability to blow the whistle "would make it possible to give the report a collective character and thus break the loneliness in which the whistleblower often finds himself, while reducing his or her exposure to the risk of retaliation"; see Opinion of the Defender of Rights n ${ }^{\circ} 20-12$ quoted by Bargain 2021 in footnote 4 . 
corruption, would, if the existing provisions are considered insufficient, require separate legislation. Another issue is the possibility of protecting organizations such as trade unions or other civil society organizations that provide assistance to whistleblowers. This issue is related to the protection of whistleblower's facilitators and will be discussed in further comments.

Another characteristic of a whistleblower, which according to Article 5(7) is the disclosure of information on breaches acquired in the context of his or her work-related activities, also requires comment. ${ }^{13}$ As explained in Article 5(9), "work-related context" means current or past work activities in the public or private sector through which, irrespective of the nature of those activities, persons acquire information on breaches and within which those persons could suffer retaliation if they reported such information. It seems to mean simply that the person obtains the information in circumstances connected with his or her work, by means of which he or she comes into contact with the institution for which he or she is carrying out that work and by means of which he or she obtains the information which he or she wishes to disclose. The inclusion of this term in the glossary of the Directive is important. Namely, the term should be understood uniformly throughout the Directive. Thus, if the Directive defines, for example, the facilitator as "person who assists a reporting person in a work-related context", this means that he/she assists the whistleblower in circumstances related to the whistleblower's work and not in circumstances related to his/her work. Moreover, it follows from the wording of the term in question that the obtaining of information, the disclosure of which is protected by the Directive, should be linked to the circumstances of the whistleblower's work, whereas such a link does not have to characterise the information itself.

There is another significant condition for the recognition of a whistleblower as a subject of protection. This is the requirement that the whistleblower must have reasonable grounds to believe that the information was true at the time of reporting and falls within the scope of the Directive. By contrast, the Directive does not require that a breach has occurred. It is rightly emphasized that whistleblowing may cause negative consequences if whistleblowers disclose information that is false. This may be the result of a deliberate act, but it may also be due to the fact that the whistleblower had reason to believe that there was a serious problem but was not in a position to know the full situation and was consequently wrong. ${ }^{14}$ The most common way to protect a whistleblower in such a situation while taking into account the rights of the entity to which the whistleblower attributed the breach is to make the protection conditional on the whistleblower acting in good faith. ${ }^{15}$

13 A similar phrase ("context of their work-based relationship") is found in the definition of the whistleblower proposed in Council of Europe, 2014, p. 6.

14 Cf. Council of Europe, 2014, p. 39.

15 See for example Article 33 of the United Nations Convention against Corruption (UNCAC), adopted by the General Assembly by resolution No. 58/4 of 31 October 2003, and the OECD definition of signalling (OECD 2016, p. 18. In turn, the ECHR held in Guya v Moldova, No. 1085/10 (No 77) that protection is extended to individuals "acting in good faith and in the belief that it 
$\mathrm{He} / \mathrm{she}$ must therefore be convinced that the conduct which is the subject of the disclosure is wrong and constitutes an breach of the law. However, this way of regulating this issue is criticized. Amongst others, it is claimed that good faith cannot be used as a condition for protecting whistleblowers because it diverts attention from the message to the motives of the messenger ${ }^{16}$ It is also argued that such shaping of the terms of protection makes it easier for persons affected by a report based on inaccurate information to question the whistleblower's motives, on which a finding of good faith depends. ${ }^{17}$ It should also be added that, in light of the practice of the UK courts, whistleblowers have had considerable difficulty in demonstrating that they are acting in good faith, resulting in the rejection of the good faith test in the Public Interest Disclosure Act 1998 in 2013 and its replacement by a reasonable belief test. ${ }^{18}$ These arguments are convincing. It is therefore welcomed that the Directive abandons the concept of good faith, replacing it with the construct of "reasonable grounds to believe". ${ }^{19}$ According to Article 6(1)(a), reporting persons are eligible for protection provided that they had reasonable grounds to believe that the reported information on the breaches was accurate at the time of reporting and that such information was within the scope of the Directive. To be sure, recital 32 clarifies that the motives of the persons making the report should not be relevant in deciding whether they should be granted protection. Furthermore, the whistleblower can report even if he or she has only suspicions that a wrongdoing occurs. ${ }^{20}$ In this light, the term "reasonable grounds to believe" does not refer to the whistleblower's belief in the veracity of the information, but to the judgment that a reasonable and objective observer in the whistleblower's situation, i.e. for example, one occupying a comparable position and possessing comparable knowledge and experience ${ }^{21}$, would make. At the same time, the whistleblower's motives are not entirely indifferent, since persons who at the time of reporting intentionally and knowingly provided false or misleading information do not enjoy protection. ${ }^{22}$ Moreover, they should be

was in the public interest to disclose it and that no other, more discrete, means of remedying the wrongdoing was available to him or her".

16 D. Lewis, The EU Directive on the Protection of Whistleblowers: A Missed Opportunity to Establish International Best Practices?, E-Journal of International and Comparative Labour Studies, Vol. 9, No. 1, January 2020, p. 18.

17 A. Savage, Whistleblowers for Change: The Social And Economic Costs and Benefits of Leaking and Whistleblowing, Open Society Foundations, https://www.opensocietyfoundations.org/ uploads/3f0ed83b-1ec2-450f-884b-5ed71d5a4769/20181120-whistleblowers-for-changereport.pdf, accessed 01/09/2021.

18 W. Vandekerckhove, Is It Freedom? The Coming About of the EU Directive on Whistleblower Protection, Journal of Business Ethics, https://doi.org/10.1007/s10551-021-04771-x, accessed 01/09/2021.

19 Such a legal solution was also recommended by the Committee of Ministers of the Council of Europe, Council of Europe, 2014, p. 9, 39.

20 Article 5(2).

21 See also Transparency International, 2019, p. 3; D. Levis, The EU Directive on the..., 2020, p. 7.

22 Recital 32. 
subject to effective, proportionate and dissuasive sanctions and be liable for damages caused by such conduct. ${ }^{23}$ A separate point should be made when a whistleblower makes a report without properly knowing whether there are reasonable grounds for reporting and whether the reported breach is covered by the Directive and, for example, reports information that is already publicly known or is unsubstantiated rumour or hearsay (recital 44). It seems that in such a case the protection should not apply if an error of judgement could have been avoided and the error is due to gross negligence of the whistleblower. ${ }^{24}$

It should be stressed that also the assessment whether a whistleblower reported information falling within the scope of the Directive depends on whether, at the time of reporting, he or she had reasonable grounds to believe so. Therefore, this assessment, too, depends on the judgment that a reasonable and objective observer in his position would have made.

In the light of recital 30, the Directive should not apply to persons who, having given their informed consent, have been identified as informants or registered as such in databases managed by authorities appointed at national level, such as customs authorities, and report breaches to enforcement authorities in return for reward or compensation. In support of this position, it was pointed out that such reports are made pursuant to specific procedures that aim to guarantee the anonymity of such persons in order to protect their physical integrity and that are distinct from the reporting channels provided for under the Directive. At the same time, in accordance with recital 62, the Directive should also grant protection where Union or national law requires the reporting persons to report to the competent national authorities, for instance as part of their job duties and responsibilities or because the breach is a criminal offence. It must be considered that these indications are consistent with the Directive as a whole and express the formal position of the legislature. For these reasons, although the recitals are not subject to transposition, ${ }^{25}$ it should be recommended that they be taken into account in the implementation of the Directive into national legislation.

In the light of the above, it also seems reasonable to conclude that the obligation to inform the employer of irregularities in the workplace, sometimes inferred from the duty of loyalty of the employee towards the employer, from the official's duty of care for the public good or the duty of the employee to have regard for the welfare of the workplace, ${ }^{26}$ does not exclude whistleblower protection under the

23 Article 23(2) and recital 102.

24 F. Kein, Whistleblowing and labour law: The Whistleblower Directive - development, content and obstacles, Italian Labour Law e-Journal, Volume 13, Issue 2, https://illej.unibo.it/article/ view/11720, accessed 01/09/2021.

25 R. Baratta, Complexity of EU Law in the domestic Implementing Process. The Theory and Practice of Legislation, Volume 2, Issue 3; December 2014, https://ec.europa.eu/dgs/legal_service/ seminars/20140703_baratta_speech.pdf, accessed 01/09/2021.

26 L. Mitrus, Z. Hajn, Labour Law in Poland, Kluwer Law International BV, Alphen aan den Rijn, 2019, pp. 104-105. 
Directive. A contrary view would lead to a serious conflict between the Directive and national law.

It also follows from the recitals that it is permissible to exclude from the circle of whistleblowers protected by the Directive persons who report complaints solely in their private interest related to a conflict with another person. This issue raises the important question whether acting in the public interest is a condition for the protection of a whistleblower. According to the classic understanding, whistleblowing means reporting in the public or social or general interest or in the general public interest, as in Article 5(b) of the EU Trade Secrets Directive. ${ }^{27}$ It is accepted in the case law of the ECHR, the Council of Europe and a number of national legislations. ${ }^{28}$ The Directive generally moves away from considering the public interest as part of the concept and condition for the protection of the whistleblower. Only the admissibility of public disclosure has been made conditional on the public interest in certain situations. This is not the case, however, for internal or external reporting. Although the Directive refers to the public interest in a number of recitals, stresses the importance of whistleblowing for the protection of the interests of the Union and of the Member States, and even links whistleblowing to the protection of the public interest, ${ }^{29}$ it does not make the protection of whistleblowers dependent on acting in that interest. At the same time, the Directive indicates how signalling systems can be relieved of reporting which is clearly not related to the protection of the public interest. Namely, in accordance with recital 22, reports concerning grievances about interpersonal conflicts between the reporting person and another worker can be channelled to other procedures. However, this indication does not imply the possibility of excluding or limiting the protection of whistleblowers motivated by an expectation of personal or financial gain. ${ }^{30}$ It is worth noting that the application of this model regulation frees the whistleblower and the entities assessing the notification from considerations of the notion of public interest and doubts as to whether the notification takes the public interest into account. At the same time, this approach makes it possible to sift out reports that are clearly not intended to protect the public interest ${ }^{31}$ and to provide protection to a wider range of whistleblowers than would be the case if the public interest concept were adopted. It is a simple instrument; it is easy to understand by the addressees of the law and

27 Directive (EU) 2016/943 of the European Parliament and of the Council of 8 June 2016 on the protection of undisclosed know-how and business information (trade secrets) against their unlawful acquisition, use and disclosure, OJ L 157, 15.6.2016, p. 1-18.

28 Judgment of ECtHR (GC) of 12 February 2008, Guja v. Moldova, appl. No. 14277/0, paras 72, 74, 76; Council of Europe, Protection of whistleblowers, Recommendation CM/Rec(2014)7 and explanatory memorandum, p. 7, https://rm.coe.int/16807096c7, accessed 01/09/2021.

29 E.g. recitals 1 and 31.

30 Otherwise ECtHR in Guja v Moldova, para. 77.

31 A similar solution was adopted under Section 5(3)(b) of the Irish Protected Disclosures Act 2014, www.irishstatutebook.ie/eli/2014/act/14/enacted/en/html, accessed 1/09/2021, see also Transparency International, 2018, p. 10. 
easy to evaluate by the authorities applying the law. At the same time, it has the good effect of not protecting notifications in the protection of an obviously private interest. If the solution suggested in recital 22 as described above is not adopted, notifications in the purely private interest will enjoy protection under the Directive.

The abandonment of the recognition of an action in the public interest as a condition for the protection of a whistleblower should, it seems, be relevant in legal proceedings concerning, for example, defamation and other cases indicated in Article 21(7). It is worth noting that the ECHR, in weighing the rights of the parties to the dispute giving rise to the complaint, e.g. the right to freedom of expression under Article 10 ECHR of that Convention, examines whether the public interest in disclosure supports granting protection to the whistleblower. ${ }^{32}$ Under the Directive, on the other hand, the prerequisite for protection (discontinuance of proceedings) is a finding that he or she had reasonable grounds to believe that the notification or public disclosure was necessary to bring the breach to light in accordance with the Directive. However, it cannot be ruled out that future case law will nevertheless take the public interest into account for such an assessment.

It follows from the above that, although the purpose of the Directive is to protect the public interest by protecting whistleblowers who report breaches of Union law, except in the case of public disclosure set out in Article 15.1(b)(i), a positive finding of an action in the public interest is not a criterion on which whistleblower protection depends. These conclusions should also apply to whistleblowers who, within the scope of the Directive, disclose business secrets obtained in a work-related context. In such a case, the defendant whistleblower will not have to prove that he or she acted in defence of the general public interest, as required by Article 5(b) of the EU Trade Secrets Directive. ${ }^{33}$

Persons who have made anonymous reports of infringements are only covered by direct protection if the Member State obliges legal entities and competent authorities to receive and follow up such reports. In such a case, if a person makes a report or a public disclosure complying with the requirements of the Directive and is subsequently identified and suffers from retaliation, he or she shall be protected under the Directive. ${ }^{34}$ This means that an anonymous person who has made a public disclosure under the conditions indicated in Article 15.1(b)(i) and has been identified is protected regardless of whether the Member State provides for the acceptance of anonymous reports through internal and external channels. The Directive also provides that where anonymous reporting is permitted under national law, it should

32 See for example Soares de Melo v. Portugal (application No.72850/14).

33 See Article 21(7) and recital 98 of the Directive. See also the critical assessment of Article 5(b) of the EU Trade Secrets Directive in V. Abazi, Trade secrets and whistleblower protection in the European Union, European Papers - European Forum, Volume 1, Issue 3, October 2016, p. 1069 https://www.europeanpapers.eu/fr/europeanforum/trade-secrets-and-whistleblower-protection-in-the-eu, accessed 01/09/2021. The Author asks inter alia: "What is precisely the scope of general public interest?".

34 Article 6(3). 
be followed up with due diligence. ${ }^{35}$ It would seem worthwhile to supplement this vague provision with a clear imposition on operators of internal and external channels of the obligation to maintain confidentiality in the event that the identity of anonymous persons is disclosed, and where their identity is ascertainable. ${ }^{36}$

As already indicated, indirect protection covers entities that have not made a report. Thus, they are not whistleblowers, but because of their connection to the whistleblower, they may be vulnerable to retaliation by the person who is the subject of the report or by another entity responding to the report in this way. As aptly pointed out, this increases protection for whistleblowers beyond the existing standard in most countries. At the same time, this is not an expression of legal generosity, but rather an adaptation to the experiences of whistleblowers and a recognition that not only they, but also others around them are vulnerable to pressure and other negative consequences. ${ }^{37}$ However, it is in fact a protection of the whistleblower himself or herself against indirect retaliation, ${ }^{38}$ although the protection granted in the Directive to third parties is obviously also in their interest. This protection is also justified on the grounds that its absence might discourage potential whistleblowers from reporting infringements. The personal scope of indirect protection has been defined by indicating three groups of entities described below. This list, unlike direct protection, is not open-ended. A comparison of the way in which the personal scopes of direct protection and indirect protection are defined in Article 4(1) and in Article 4(4), respectively, indicates the intention of the legislature to limit the entities covered by indirect protection to the indicated three groups of entities. The possibility of extending this protection to other entities would have to be based on an expansive interpretation of Article 25(1), which empowers Member States to adopt provisions that are more favourable to the rights of persons making a notification. Literalistically, extending the personal scope of indirect protection is not tantamount to the adoption of provisions more favourable "to the rights" of whistleblowers. It is, however, a measure more favourable to whistleblowers, as Article 25(1) has been interpreted in recital 104. Indeed, as indicated above, indirect protection is in essence the protection of whistleblowers against indirect retaliation.

Among the persons covered by indirect protection, the Directive places facilitators in the first place. A facilitator is a natural person who assists the whistleblower

35 Article 9.1(e).

36 Such an order is provided for by Article 53.2(5) of the Polish Act of 1 March 2018 on the prevention of money laundering and terrorist financing, Journal of Laws (2018) item 723, implementing Directive 2015/849/EU of 20 May 2015 on the prevention of the use of the financial system for money laundering or terrorist financing.

37 V. Abazi, The European Union Whistleblower Directive: A 'Game Changer' for Whistleblowing Protection?, Industrial Law Journal, Volume 49, Issue 4, December 2020, p. 648.

38 Recital 41. 
in the reporting process in a work-related context. This should be understood as assistance related to the whistleblower's work, whereby the whistleblower obtains information about violations. ${ }^{39}$ Assistance may consist, for example, in facilitating access to sources of information, giving advice on procedures, assisting in writing a report, etc. The facilitator should be protected from disclosure of the fact that assistance has been provided. ${ }^{40}$ As explained in recital 41 , facilitators who provide advice and support to the whistleblower can also be trade union representatives or other employees' representatives. They are then subject to protection both granted under the Directive and afforded to them under other EU and national rules on the status of employees' representatives. On the other hand, trade unions as such, i.e. as legal persons, do not fall within the role of facilitators as defined in the Directive. For the same reason, other civil society organizations do not fall within it, either, despite requests made. ${ }^{41}$

It seems that support and protection for such organizations is needed. However, it should be, if national law does not provide it, introduced by a specific regulation other than a directive explicitly aimed at the protection of individuals. In turn, workers and activists of such organizations remain outside the personal scope of the Directive, as they do not act in a work-related context. Extending the protection against retaliation to them as natural persons seems justified. However, this would have to entail extending the notion of facilitator also to other natural persons operating outside a work context. Indeed, they may, due to their lack of organizational support, be more vulnerable to retaliation than civil society activists.

In the light of the Directive, the protection of facilitators is limited to persons assisting in the process of making a report, omitting persons assisting the whistleblower after the report has been made, e.g. protecting the whistleblower from being exposed or opposing unfavourable actions taken against him or her. Therefore, it seems justified to extend the protection of facilitators also to this group.

A person who discloses information that supplements information on breaches previously disclosed by another person should be distinguished from a facilitator. Such a person should be regarded as a separate whistleblower. ${ }^{42}$

The indirect protection under the Directive extends also to third parties such as colleagues or relatives of the reporting person who are also in a work-related connection with the reporting person's employer or customer or recipient of services. ${ }^{43}$

39 Article 4.4(a) and Article 5(8).

40 Article 5(8).

41 Transparency International sees a need to protect such organizations in their role as facilitators, pointing out that defining a facilitator in the Directive as an individual excludes civil society organizations that provide advice and support to whistleblowers. This exposes these organizations to retaliation and pressure to reveal the identity of the whistleblower, which jeopardizes their essential work done to protect whistleblowers and help them uncover wrongdoings that need to be addressed to safeguard the public interest; See: Transparency International (2019), pp. 5-6.

42 Otherwise, it seems, Transparency International (2018), p. 11.

43 Article 4.4(b); recital 41. 
The personal scope of the protective provisions of the Directive is completed by the reference to legal entities that are owned by the reporting person, for which he/ she works or with which he/she is otherwise connected in a work-related context. The group of these entities thus extends beyond natural persons. As indicated in recital 41, the aim is to counter such indirect retaliatory behaviour as, for example, refusal to provide services, blacklisting or boycotting a business. Article 4.4(c) also does not appear to justify the inclusion of trade unions as protected entities. It is true that, literally, a trade union representing the interests of a whistleblower could be considered to be associated with the whistleblower in a work-related context, but it is difficult to imagine against what kind of retaliation it would be protected as a legal person. The protection of trade union officials or other employee representatives as facilitators of the whistleblower and the protection of unions and their activists arising from freedom of association would seem sufficient.

Finally, some calls in subject literature for an extension of legal protection beyond the personal scope adopted in the Directive require attention. This applies in particular to persons who only intend or attempt to disclose information and to persons who do not disclose or do not even intend to report but are suspected of having done so or may do so. Examples include situations when an employee asks questions related to a breach, discloses his or her knowledge of a breach without even realizing that he or she is talking about a breach, or advises co-workers or superiors about a perceived breach. It is pointed out that, for these reasons, these individuals may experience prejudicial treatment aimed at discouraging them from disclosing the information or be subject to "pre-emptive action", such as transfer to another position or dismissal to circumvent legal protection. In other words, in certain circumstances the perception (typification) of someone as a whistleblower may result in retaliation. The protection as whistleblowers of persons who try to expose irregularities or are perceived as whistleblowers has been advocated among others by Transparency International. ${ }^{44}$ Moreover, the Committee of Ministers of the Council of Europe recommends that the prohibition on retaliation should cover situations where an employer recommends, threatens or attempts to retaliate against a potential whistleblower, pointing out that such actions may have a chilling effect on the whistleblower, who as a result may be deterred from properly reporting the problem. ${ }^{45}$

There is no doubt that these persons deserve protection if the described circumstances are the cause of repression. Indeed, the exertion of pressure on them, in the form of adverse actions, may be regarded by legal entities (employers) as a means of preventing disclosure of breaches. The protection of these persons is currently limited to requiring Member States to impose a prohibition on obstructing or attempting to obstruct reporting under the pain of sanctions ${ }^{46}$ Such protection does

44 See Transparency International 2019, Transparency International 2018.

45 Council of Europe, 2014, p. 38.

46 Article $23(1)(a)$. 
not appear to be sufficient, however, as punishing the offender does not remedy the harm suffered through retaliation. Such protection should be afforded, for example, by expressly providing in national legislation for the general rule that a person suspected of whistleblowing and intending or attempting to carry out whistleblowing may not suffer retaliation for doing so in a work-related context. While even without such an explicit provision in the law, the disclosure of such circumstances in court proceedings should result in the court granting protection by, for example, declaring the termination of the employment contract or another act of the employer to be defective, this could prove ineffective, for example, in a case for damages for the termination of a civil contract, where the reason for termination is often irrelevant. Stronger protection would be provided by an appropriate application of Chapter VI of the Directive to the above-mentioned groups of persons.

\section{Who is obliged to carry out the obligations imposed by law in relation to the protection of whistleblowers and responsible for doing that?}

In the light of the Directive, a number of entities can be distinguished as being obliged and responsible for failure to comply with primary and derived protection obligations. These obligations relate in particular to: the establishment and operation of channels for receiving reports and taking follow-up action, the supervision, coordination and provision of support measures to whistleblowers and other protected persons, and the prohibition of retaliation. These entities include, in particular, the legal entity, the competent authority, persons acting on their behalf or in their stead, the entity or entities providing support measures, and entities implementing retaliatory measures.

The description and characterization of all these subjects and their duties and responsibilities would require a separate and extensive study, especially as the decision as to the very definition of their group and their responsibilities depends to a large extent on the Member States and on those operating the notification channels and those providing support to protected persons.

For these reasons, I will limit further comments to two issues, one general and one specific. The first (general) refers to liability for non-performance or improper performance of duties.

The Directive does not generally regulate or even give guidance on this issue. The only provisions dealing explicitly with the liability under consideration are Articles 21(8) and 23(1). The former deals with compensation for the harm suffered by the whistleblower through remedies such as restitution or damages. The latter obliges Member States to establish effective, proportionate and dissuasive penalties 
applicable to natural or legal persons who obstruct or attempt to obstruct a report, retaliate or instigate nuisance proceedings against protected persons or violate the obligation to keep the identity of reporters confidential. This regulation highlights the wide range of persons who may be subject to sanctions. Indeed, they may be not only the so-called legal entities (as legal or natural persons) operating the internal channels and the so-called "competent authorities" as entities designated to operate the external channels, but also their employees carrying out certain duties in this respect, third parties entrusted with the operation of the internal channel or with the follow-up, or even staff members of the competent authority not authorized to receive notifications received in error.

However, beyond the scope of Articles 21(8) and 23(1), there remains a complex of issues that need to be addressed in national legislation in order to ensure the operability and effectiveness of the whistleblowing system. This concerns in particular issues such as sanctions for lack of follow-up, breach of deadlines for the provision of feedback, failure to provide the required information, failure to comply with the obligations imposed on competent authorities by Articles 11 to 13 of the Directive, and failure to fulfil or inadequate fulfilment of duties in relation to the provision of support measures. Of course, not all rules of liability for the violations indicated as examples must be explicitly regulated in the provisions implementing the Directive. In many cases, they may result from the general rules of labour, civil, administrative or criminal liability. However, what seems to be needed is a clear indication of the principle of liability of the obliged entities, the establishment of specific sanctions in cases where the general principles of legal liability are not sufficient, as well as a clear definition in national law of the scope of duties of individual entities. This could be done in statutory provisions or, for example, in by-laws and other internal acts of legal entities and competent authorities that set out the rules and procedures for the operation of internal and external channels. It would be desirable to give these internal rules the force of law as sources of rights and obligations. Where appropriate, it would also be useful to regulate the means of intervention available to whistleblowers, e.g. in the case of untimely handling of reports, failure to provide confirmation of reporting, etc. The persons concerned should be clearly and precisely informed about the above issues.

Of the specific issues, it seems most important to clarify the concept of the legal entity, i.e. the entity obliged to set up and ensure the functioning of the internal channels. These channels are of fundamental importance for the purposes of the Directive. Their establishment and smooth functioning, trusted by whistleblowers, is also in the direct interest of the institutions in which they should be set up, because of not only the chance to clean up irregularities in the organization, but also the chance to deal with the matter "on the spot", without it becoming known to external bodies or receiving publicity. 
In the Directive, these entities are usually referred to as "legal entities" or "organizations". Occasionally, the terms "employer" 47 or "undertaking" 48 are used. The occasional use of the latter two terms is understandable, since the entity obliged to establish an internal channel need not be an employer or an undertaking, although it is most often both. The terms "employer" and "undertaking" therefore fall within the meaning of "legal entity" or "organization". At the same time, the terms "legal entity" and "organization" reflect the subjective and objective faces of the same concept. ${ }^{49}$ It follows from the provisions and recitals of the Directive that it is an organization where the breaches have occurred or are likely to occur and where the reporting person works or has worked, or another organization, with which the reporting person is or was in contact through his or her work..$^{50}$ It is also the entity within which the breaches which are the subject of an internal notification take place ${ }^{51}$ and which has the capacity to deal effectively with the report. ${ }^{52}$ It is also worth noting that these legal entities are most often "persons concerned", i.e. persons who are referred to in the report or are organs or employees of the entity.

The use of the inclusive term "legal entity" and not the terms "natural person" and "legal person" justifies the thesis that the basis of legal capacity is not a defining criterion for a "legal entity". ${ }^{33}$ The role of "legal entity" and the semantic contexts in which the term, with one exception, ${ }^{54}$ appears in the Directive support the conclusion that it can cover both natural and legal persons, as well as associations of persons or organizational entities having legal capacity, despite the lack of legal personality, such as general partnerships and partnerships under some national laws. It is essential that it is a unit in which, by virtue of its separation and having its own set of workers and collaborators and tasks, there may be breaches for which an internal channel is needed and that it is equipped with the legal powers to respond appropriately to breaches in accordance with the procedures for the operation of such a channel. It is desirable, however, that that entity should be able to take legal responsibility. It is, in fact, as has been pointed out, most often the person who is the "person concerned" by the report or who is the object of the report, whether it concerns an organ or an employee. Therefore, the Directive defines the "person concerned" as a natural or legal person who is referred to in the report or public

47 Recital 47.

48 E.g. Article 4(1)(c).

49 In the Directive, the term "legal entity" is most often used in personal meaning, while "organization" in the objective one. But this is not a rule without exceptions, e.g. Article 5(4) mentions "information on breaches within a legal entity".

50 Article 5(2), recital 1, 33, 45.

51 Article 5(4).

52 Recital 47.

53 Similarly for example, in recital 8 and Article 2(c) of the Directive 2009/52/EC of the European Parliament and of the Council of 18 June 2009 providing for minimum standards on sanctions and measures against employers of illegally staying third-country nationals.

54 See Article 4(4)(c). 
disclosure as a person to whom the breach is attributed or with whom that person (i.e. person to whom the breach is attributed) is associated. The person identified as the infringer therefore ought to be a natural or legal person, as this guarantees the capacity to bear legal liability, in particular civil liability for damages. As seems appropriate, entities having under national law legal capacity equivalent to legal personality, such as certain companies without legal personality, should be put on an equal footing. However, the lack of such capacity should not disqualify an entity from being a legal person within the meaning of the Directive. In such a case, the law should ensure that legal liability is borne by the natural or legal persons who "stand behind" such an entity, such as a company behind its branch. ${ }^{55}$

The specificity of the concept of "legal entity" in the Directive is further revealed in relation to groups of undertakings. Internal reporting procedures should enable legal entities in the private sector to receive and investigate in full confidentiality reports by the workers of the entity and of its subsidiaries or affiliates ("the group"), but also, to any extent possible, by any of the group's agents and suppliers and by any persons who acquire information through their work-related activities with the entity and the group..$^{56}$ The establishment of an internal channel at group level does not prevent it from also being set up at the level of the individual companies in the group. Moreover, it is compulsory for entities with at least 50 employees.

It should be added that a whistleblower may make reports through several internal channels administered by legal entities with which he or she has a working relationship.

\section{Conclusions}

Protection of whistleblowers is subsidiary to the objective of the Directive, which is to protect the public interest by improving the enforcement of laws and policies of the Union. As a result, doubts as to the personal scope of protection of whistleblowers must be clarified, taking into account the above mentioned objective of the Directive. This protection has a wide personal scope. In addition to whistleblowers, it also covers persons associated with the whistleblower who may suffer retaliation for that reason. The rationale for extending protection to related persons is to protect whistleblowers from indirect retaliation. This is how its scope and conditions should be explained. Therefore, on the basis of the Directive, it is justified to

55 This problem may concern countries such as Poland, where the status of employer is also granted to entities without legal personality, if they have the so-called capacity to hire employees. This applies in particular to governmental organizational units, local government units and separate internal units of private sector companies.

56 Recital 55. 
distinguish between direct (whistleblowers) and indirect (persons associated with the whistleblower) protection.

A whistleblower under the Directive is a "reporting person", i.e. a natural person who reports or publicly discloses information on breaches acquired in the context of his or her work-related activities. The list of persons who can be considered whistleblowers contained in Article 4 is minimal. Any reporting person in the sense given above should be considered a whistleblower. The relationship that such persons have with the organisation to which the whistleblowing relates is referred to in the Directive as a "work-based relationship". This concept cannot be equated with an employment relationship.

The status of a whistleblower ("reporting person") does not in itself ensure legal protection. To benefit from it, a whistleblower must fulfil further conditions. In particular, he/she must have reasonable grounds to believe that the disclosed information was true at the time of reporting and falls within the scope of the Directive. The term "reasonable grounds to believe" does not refer to good faith, i.e. the whistleblower's belief in the veracity of the information, but to the assessment that a reasonable and objective observer in his/her situation would make. However, persons who, at the time of reporting, have intentionally and knowingly provided false or misleading information do not enjoy protection. Moreover, obtaining protection generally does not depend on a positive finding that the whistleblower acted in the public interest. However, whistleblowers who report complaints solely in their private interest related to a conflict with another person should be excluded from the circle of protected whistleblowers. Similarly, a person recognized or registered as paid whistleblower does not enjoy protection, either.

Indirect protection covers the whistleblower's facilitators, third parties associated with the whistleblower and legal entities owned by the whistleblower or otherwise associated with him or her. It would be advisable to extend the group of entities covered by that protection to include persons assisting the whistleblower after the report has been made as well as persons intending or attempting to disclose information and persons suspected of being whistleblowers if the aforementioned persons suffer retaliation for those reasons.

Under the Directive, a number of entities can be distinguished as obliged and responsible for failure to comply with obligations relating to direct or indirect protection. These obligations relate in particular to the establishment and functioning of channels for receiving and following up on reports, the supervision, coordination and provision of support measures to whistleblowers, and the prohibition of retaliation. In principle, apart from Articles 21(8) and 23(1), the Directive does not regulate, or even give guidance on, the liability of obliged entities for non-performance or poor performance of obligations. For this reason, it seems necessary to clearly establish the principle of liability of the obliged entities for non-performance or improper performance of signalling obligations, to provide for specific sanctions in the event that the general principles of legal liability are not sufficient, and to clarify in national law the scope of the obligations of the 
various entities. It would also be appropriate to regulate the means of protection and intervention available to whistleblowers, e.g. in the case of untimely handling of reports, etc. The persons concerned should be clearly and precisely informed about the above-mentioned issues.

\section{Abstract}

The aim of this chapter is to present selected problems related to the transposition into national law of the provisions of the Directive (EU) 2019/1937 which define the personal scope of its application. The author focuses on the prerequisites for recognising a given person as a whistleblower (reporting person) and including them in the circle of protected persons. Among other things, he considers issues related to the Directive's departure from the recognition of acting in good faith and in the public interest as conditions for the protection of a whistleblower, as well as the relevance for the protection of a whistleblower of the obligation to report breaches existing in some national laws. He also argues that the relationship that whistleblowers enter into with the organisation affected by the whistleblowing, referred to in the English version as a "work-based relationship", cannot be equated, as other language versions do, with an employment relationship. The author also proposes, following earlier postulates, to extend the personal scope of protection of facilitators. $\mathrm{He}$ also attempts to clarify the notion of "legal entity" as the main entity responsible for the creation and functioning of internal channels. He further postulates more complete regulation in national legislation of the rules of liability of entities responsible for fulfilling the obligations imposed by the Directive.

\section{Bibliography}

Abazi V., The European Union Whistleblower Directive: A 'Game Changer' for Whistleblowing Protection?, Industrial Law Journal, Volume 49, Issue 4, December 2020.

Abazi V., Trade secrets and whistleblower protection in the European Union, European Papers - European Forum, Volume 1, Issue 3, October 2016. https://www.europeanpapers. $\mathrm{eu} / \mathrm{fr} /$ europeanforum/trade-secrets-and-whistleblower-protection-in-the-eu, accessed 01/09/2021.

Baratta R., Complexity of EU Law in the domestic Implementing Process. The Theory and Practice of Legislation, Volume 2, Issue 3; December 2014, https://ec.europa.eu/dgs/legal_service/seminars/20140703_baratta_speech.pdf, accessed 01/09/2021.

Bargain G., Shortcomings in the Workplace whistleblowers' protection in France. What to expect from the transposition of the directive 2019/1937? Chapter published in this monograph.

Garlicki L. (ed.), Konwencja o ochronie Praw Człowieka i Podstawowych Wolności (Convention for the Protection of Human Rights and Fundamental Freedoms), commentary to Article 10, Vol. I, No. 57, Warsaw 2010. 
Kein F., Whistleblowing and labour law: The Whistleblower Directive - development, content and obstacles, Italian Labour Law e-Journal, Volume 13, Issue 2, https://illej.unibo.it/ article/view/11720, accessed 01/09/2021.

Lewis D., The EU Directive on the Protection of Whistleblowers: A Missed Opportunity to Establish International Best Practices?, E-Journal of International and Comparative Labour Studies, Vol. 9, No. 1, January 2020.

Mitrus L., Hajn Z., Labour Law in Poland, Kluwer Law International BV, Alphen aan den Rijn, 2019.

OECD 2016, Committing to Effective Whistleblower Protection, https://dx.doi.org/10.1787/ 9789264252639-en, accessed 01/09/2021.

Savage A., Whistleblowers for Change: The Social And Economic Costs and Benefits of Leaking and Whistleblowing, Open Society Foundations, https://www.opensocietyfoundations. org/uploads/3f0ed83b-1ec2-450f-884b-5ed71d5a4769/20181120-whistleblowers-forchange-report.pdf, accessed 1/09/2021.

Transparency International, A Best Practice Guide for Whistleblowing Legislation, https:// images.transparencycdn.org/images/2018_GuideForWhistleblowingLegislation_EN.pdf, accessed 01/09/2021.

Transparency International, Building on the EU Directive for whistleblower protection, Analysis and Recommendations, Position Paper, 1/2019, https://www.transparency.org/en/publications/building-on-the-eu-directive-for-whistleblower-protection, accessed 01/09/2021.

Vandekerckhove W., Is It Freedom? The Coming About of the EU Directive on Whistleblower Protection, Journal of Business Ethics, https://doi.org/10.1007/s10551-021-04771-x, accessed 01/09/2021.2021. 